\title{
Framing Pemberitaan BangkaPos.com tentang Razia Tambang Timah Illegal di Propinsi Bangka-Belitung
}

\author{
https://doi.org/10.25008/caraka.v1i1.39 \\ EKO TEJO MARVIANTO \\ AHMAD TONI \\ Universitas Budi Luhur - Indonesia
}

\begin{abstract}
This research aims to see how the news framing of news portal BangkaPos.com in reporting a crackdown on illegal tin mining in its editions on November 2019 and March 9, 2020. The selection of news portal Bangkapos.com was based on the consideration that it is the only local daily newspaper that consistently reviews and reports the issue. This research uses Zhongdan Pan and Gerald M. Kosicki framing model. This research was conducted through qualitative approaches based on constructivist paradigm. The results of this research suggest that the news framing points to power politics with regard to a physical clash between miners and Public Order Agency (Satpol PP) personnel in Sijuk Village, Belitung Regency.
\end{abstract}

Keywords: Framing; Bangkapos; illegal mining; power politics; Satpol PP

\section{ABSTRAK}

Penelitian ini bertujuan melihat bagaimana framing pemberitaan portal berita BangkaPos.com dalam memberitakan razia tambang timah illegal edisi bulan November 2019 dan 9 Maret 2020. Portal berita Bangkapos.com dipilih berdasarkan pertimbangan Bangkapos.com secara terus menerus mengulas dan memberitakan insiden kekerasan yang terjadi pada razia tersebut. Model framing yang digunakan adalah model Zhongdan Pan dan Gerald M. Kosicki. Penelitian dilakukan dengan pendekatan kualitatif berdasarkan paradigma konstruktivis. Hasil dari penelitian ini adalah framing pemberitaan mengarah pada adanya politik kekuasaan dalam peristiwa terjadinya bentrok fisik antara para penambang dengan Satpol PP di Desa Sijuk, Kabupaten Belitung, Propinsi BangkaBelitung.

Kata kunci: Framing; Bangkapos; tambang illegal; politik kekuasaan; satpol PP

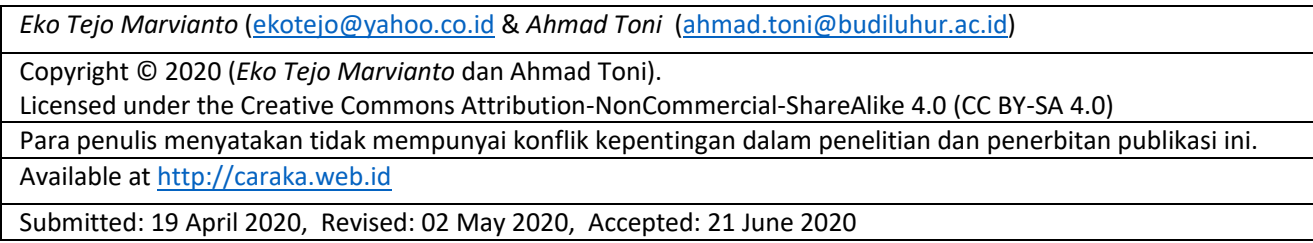




\section{PENDAHULUAN}

Portal Berita BangkaPos.com melakukan fungsi kontrol pemberitaan dengan menerbitkan berita yang mengkritisi peristiwa pengepungan massa kepada rombongan Satuan Polisi Pamong Praja (Satpol PP) dan Wakil Gubernur Bangka Belitung saat melakukan razia tambang timah ilegal di Kecamatan Sijuk, Kabupaten Belitung melalui pemberitaan intensif pada November 2019 dan 9 Maret 2020.

Pemberitaan soal tambang illegal di Bangka Belitung dari dulu sampai sekarang sering menjadi berita utama (headlines news) di media massa setiap terjadi konflik, seperti yang terjadi pada peristiwa 2 November 2019. Bangkapos.com memberitakannya dengan judul: "Wagub Abdul Fatah Dikabarkan Dikepung Warga di Sijuk Belitung, 6 Satpol PP Terluka" (Gambar 1).

Berita itu menyebutkan, kericuhan terjadi saat penertiban Tambang Inkonvensional (TI) di aliran Sungai Sengkelik, Desa Sijuk, Kecamatan Sijuk, Kabupaten Belitung.

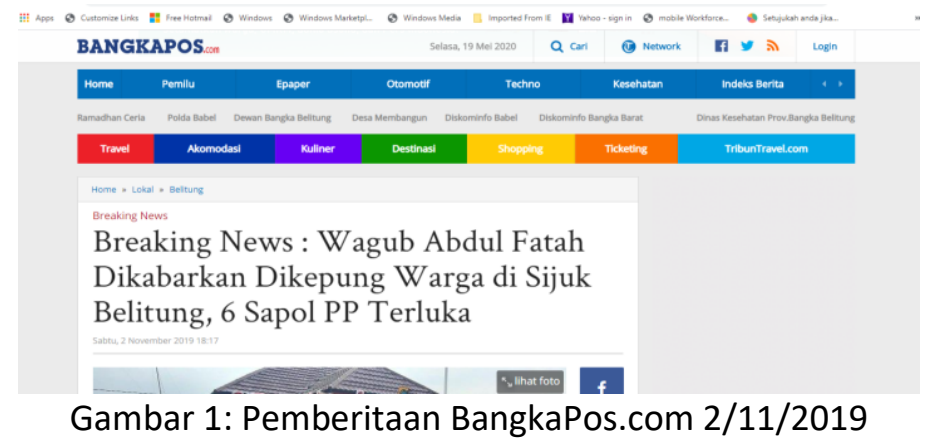

Konflik merupakan salah satu peristiwa yang selalu menarik untuk diberitakan (Ritonga et al, 2019; Ritonga \& Syahputra, 2019), terlebih bila menyangkut figur publik. Hal itu menarik untuk diberitakan oleh media dan dikonstruksikan dengan bingkai tertentu. Bingkai yang dibuat bisa positif ataupun negatif serta dipengaruhi banyak faktor (Maryani, 2018). Setiap media memiliki kepentingan dan kecenderungan berbeda terhadap suatu permasalahan. Inilah yang menyebabkan terjadinya perbedaan antara media yang satu dengan lainnya dalam memberitakan satu peristiwa yang sama.

Melakukan pembingkaian bisa dilakukan dengan berbagai cara. Salah satunya dengan menampilan suatu peristiwa secara berulang-ulang untuk masa waktu tertentu. Semakin sering suatu berita dimunculkan, berarti media tersebut menganggap peristiwa itu penting bagi mereka, dan berati penting pula bagi masyarakat (Suraya, 2019).

Bangka Pos, misalnya, media massa yang berdiri tahun 1999 dengan tagline 'Yo Kita Punya Provinsi' itu selalu tampil dengan berita-berita headline bila menyangkut berita bernilai tinggi seperti razia tambang timah illegal berujung bentrokan antara penambang liar dengan Satpol PP dan wakil gubernur yang hadir di tempat itu bersama aparat Satpol PP.

Penelitian ini mencoba mendalami permasalahan peristiwa pemberitaan tersebut dengan tujuan melihat pembingkaian berita yang dilakukan Bangkapos.com sebagai media massa lokal di Bangka-Belitung dalam mengulas dan memberitakan permasalahan razia tambang illegal itu secara terus menerus dengan segala implikasinya.

Pemberitaan BangkaPos.com itu dilihat dengan menggunakan framing model Zhongdan Pan dan Gerald M. Kosicki terutama dalam mengkonstruksi bentrok fisik yang melibatkan Wakil Gubernur Bangka Belitung Abdul Fatah. 


\section{KERANGKA TEORI}

Media massa, termasuk media cetak, elektronik maupun media online merupakan sarana yang digunakan untuk melakukan komunikasi massa. Ciri-ciri dari komunikasi massa antara lain audience-nya besar dan tersebar luas, pesan bersifat umum dan komunikatornya merupakan suatu organisasi yang kompleks (Tamburaka, 2012: 15).

Komunikasi massa juga merupakan kegiatan yang berkaitan dengan jurnalistik. Menurut Onong Uchjana Effendi dalam Suryawati, jurnalistik memiliki memiliki empat fungsi, yaitu to inform, to educate, to entertain dan to influence (Suryawati, 2011: 38-39).

Komunikasi massa dapat didefinisikan sebagai proses penyampaian pesan dari organisasi dengan memanfaatkan teknologi untuk menjangkau audience yang besar (Baran, 2009; Ritonga et al, 2017). Teknologi di sini merupakan media yang digunakan dalam penyampaian pesan, bisa media cetak, elektronik, maupun internet.

Ada dua pandangan mengenai media, yaitu pandangan dari kalangan positivistik yang menganggap media sebagai saluran bebas, dan pandangan dari konstruktivis, yang menganggap media sebagai agen dari konstruksi realitas.

Dalam penelitian ini, media dipandang sebagai agen dari konstruksi sosial yang mendefinisikan suatu realitas (Eriyanto, 2002: 23). Dalam pandangan itu, bias berita terjadi karena media massa tidak berada di ruang vakum. Media berada di tengah realitas sosial yang sarat dengan berbagai kepentingan, konflik, dan fakta yang kompleks dan beragam (Sobur, 2012: 29).

Tony Bannet dalam Eriyanto menyatakan, dalam pandangan konstruksionis, media dipandang bukan saja sebagai saluran yang bebas. la subjek yang mengkonstruksi realitas, lengkap dengan pandangan, bias, dan pemilihannya. Di sini, media dipandang sebagai agen konstruksi sosial yang mendefinisikan realitas (Eriyanto, 2002: 23).

Dalam melakukan kegiatan jurnalistik, wartawan melakukan konstruksi terhadap fakta di lapangan untuk disampaikan ke audience melalui media. Ada pandangan penting mengenai media. Pandangan ini berasal dari paham konstruksionis. Paham ini menganggap media bukan hanya sebagai saluran, tapi juga sebagai agen yang melakukan konstruksi terhadap suatu realitas berdasarkan unsur-unsur tertentu (Eriyanto, 2002: 22-23).

Tiap media memiliki unsur berbeda-beda, sehingga konstruk yang dihasilkan media satu dengan lainnya berbeda pula. Hal ini bisa juga termasuk kepentingan internal masingmasing media tersebut.

\section{Kontruksi Realitas Sosial}

Karakteristik media memiliki pengaruh yang besar dalam kehidupan politik dan budaya masyarakat (Morrisan, 2012: 1). Efek langsung pemberitaan media bisa berupa popularitas yang meningkat karena kemunculan di media.

Kemampuan media dalam mengkonstruk realita inilah yang membuat pemerintah harus menjaga hubungan baik dengan media massa, sebab media sering menyoroti masalah pemerintahan dan politik, sehingga pemerintah perlu menjaga hubungan dengan media agar citra dan reputasi mereka tetap terjaga (Iriantara, 2008: 4).

Mengutip Littlejohn dan Foss dalam Morissan (2010: 48-49), ada empat tipe hubungan pemerintah dengan media yaitu:

(1) High-power source, high-power media yakni, antara pemerintah dan media samasama memiliki kekuatan yang besar. Jika menjalin kerjasama yang baik, bisa memberikan pengaruh yang besar pada agenda publik: 
(2) High-power source, low-power media; media memiliki kekuatan yang lebih rendah dari pemerintah. Dalam praktiknya di suatu pemerintahan jika terjadi tipe ini, maka media akan digunakan untuk mencapai tujuannya;

(3) Low-power source, high-power media: kekutan media lebih besar, sehingga bebas untuk menentukan agendanya sendiri, serta dapat pula memberitakan, menambah ataupun mengurangi intensitas pemberitaan tertentu, terhadap suatu peristiwa;

(4) Low-power source, low-power media; yakni agenda media ditentukan oleh peristiwa itu sendiri, bukan dari media ataupun pemerintah.

Pandangan kedua dari Erving Goffman seperti dikutip Eriyanto (2002). Goffman berpendapat setiap manusia akan mengklasifikasikan dan mengorganisasikan kegiatan peristiwa kesehariannya, kemudian menjadikannya sebagai realitas setelah melalui tahap pendefinisian situasi. Hal ini akan mempengaruhi frame seseorang terhadap realitas sosial (Eriyanto, 2002: 81).

McQuail, mengelompokkan bidang kajian komunikasi menjadi empat, yang berasal dari persilangan antara media massa dengan masyarakat dan kebudayaan. Empat bidang kajian komunikasi massa tersebut (McQuail, 2011: 14) adalah:

(1) Perspective media culturalist yaitu lebih menitikberatkan pada isi dan penerimaan isi (pesan media) oleh khalayak dan penekanan makna subjektif dari pengalaman terkait konteks tertentu;

(2) Perspective media materialist, menekankan pada pembentukan konten dan efek potensial, berkaitan dengan teknologi dan hubungan sosial dalam penerimaan dan produksi. Selain itu juga menekankan pada pengaruh dari konteks struktural dan dinamika suatu produksi media;

(3) Perspective social culturalist, menekankan bahwa media berada di bawah pengaruh kekuatan yang lebih besar dalam mempengaruhi masyarakat dan individu. Isu sosial dan budaya lebih mendominasi;

(4) Perspective social materialist, pandangan kritis pada kepemilikan dan kontrol media yang membentuk ideologi dominan dalam penyiaran.

McQuail juga menyoroti pentingnya peranan media massa dalam proses terjadinya komunikasi massa. Menurut McQuail dalam Morissan (2010), media massa memiliki karakteristik dapat menjangkau massa yang tersebar karena sifatnya publik dan memiliki konsekuensi secara langsung maupun tak langsung pada beberapa pihak.

Karakteristik media sendiri juga sebenarnya memiliki pengaruh yang besar dalam kehidupan politik dan budaya masyarakat karena karakteristik ataupun sifatnya itu (Morisan, 2010: 1).

Tokoh dari dimensi sosiologis ini antara lain ada Erving Goffman dan Peter L. Berger. Dikutip Eriyanto, Berger menganggap realitas dibentuk dan dikonstrusi, jadi bukan dibentuk secara ilmiah. Hal ini menyebabkan setiap orang bisa memiliki konstruk yang berbeda-beda terhadap suatu realitas (Eriyanto, 2002: 15).

\section{Framing}

Menururut Tuchman dalam Pawito (2007), framing mengorganisasikan realitas sehari-hari dan frame berita adalah bagian dan kemasan dari realitas sehari-hari (Pawito, 2007: 188). Sosiolog Erfin Goffman (1974) dalam Baran menjelaskan, analisis frame adalah analisis yang digunakan untuk memberikan pemahaman sistematis mengenai bagaimana menggunakan pengharapan dan memaknai situasi sehari-hari dari orang-orang yang ada di dalamnya (Baran, 2009: 392). 
Secara umum, framing dapat dirumuskan sebagai proses penyeleksian dan penonjolan aspek-aspek tertentu dari realitas yang tergambar dalam teks komunikasi dengan tujuan agar aspek itu menjadi lebih noticeable, meaningfull dan memorable bagi khalayak (Sudibyo, 2001: 221).

Framing bisa digunakan sebagai teori maupun sebagai metode analisis. Framing sebagai teori dapat dilihat dalam dua tradisi.

Pertama, dimensi psikologis yang mengungkap jika pesan atau realitas dibentuk melalui kerangka berpikir dan digambarkan dengan cara tertentu guna menyederhanakan suatu realitas. Proses pembuatan pesan inilah, yang membuat suatu realitas memiliki bingkai, perspektif atau dimensi tertentu (Eriyanto, 2002: 72-79).

Kedua, dimensi sosiologis yang menganggap frame media membuat realitas kehidupan sehari-hari dan mentransformasikannya dalam bentuk cerita, yang memungkinkan seseorang untuk mengorganisasikan pengalamannya guna memahami suatu peristiwa serta memaknai dan mengidentifikasikannya (Eriyanto, 2002: 79-82).

Framing dapat terjadi karena adanya tuntutan teknis terkait keterbatasan kolom dan halaman, sehingga suatu media tidak memuat keseluruhan peristiwa secara utuh. Media memilah dan menyeleksi apa yang akan disampaikan pada publik berdasarkan pada kaidahkaidah jurnalisme. Peristiwa yang panjang dan rumit "disederhanakan" dengan melakukan pembingkaian (framing) terhadap fakta-fakta untuk diterbitkan (Hamad, 2004: 21).

Media massa tidak bisa menyampaikan keseluruhan peristiwa yang terjadi secara detail dalam berita. Hal ini kemudian mempengaruhi wacana yang dibentuk oleh media massa. Fakta-fakta ada yang ditonjolkan dan ada yang disembunyikan, tergantung dari kepentingan dan kebijakan media massa. Selain itu, mengutip Van Dijk dalam Hamad, framing bisa digunakan sebagai teori maupun sebagai metode untuk membedah suatu wacana (Hamad, 2004: 21-22).

Dalam penelitian ini Framing yang digunakan adalah model Zhongdan Pan dan Gerald M. Kosicki yang berpegang pada struktur: sintaksis, skrip, tematik dan retoris. Menurut Zhongdan Pan dan Gerald M. Kosicki, framing melibatkan dua konsepsi yakni: (1) konsepsi psikologis yang melihat frame semata-mata sebagai persoalan internal pikiran, dan (2) konsepsi sosiologis yang lebih tertarik melihat frame dari sisi bagaimana lingkungan sosial dikontruksikan seseorang.

Framing dipahami sebagai perangkat kognisi yang digunakan dalam informasi untuk membuat kode, menasirkan, dan menyimpannya untuk dikomunikasikan dengan khalayak yang kesemuanya dihubungkan dengan konvensi, rutinitas, dan praktik kerja professional wartawan. Framing lalu dimaknai sebagai suatu strategi atau cara wartawan dalam mengkontruksi dan memproses peristiwa untuk disajikan kepada khalayak (Eriyanto, 2003:253).

\section{METODOLOGI}

Penelitian ini adalah penelitian kualitatif, menggunakan paradigma kontruktivis untuk melihat teks berita berpedoman pada framing terhadap analisa berita secara tekstual dan elemen berita. Sifat penelitian ini bukan untuk menguji teori, tetapi hanya untuk menggambarkan suatu fenomena yang terjadi.

Data primer berasal dari BangkaPos.com yang berkaitan dengan pemberitaan Wakil Gubernur Bangka Belitung dikepung saat berlangsungnya razia tambang edisi 2 November 2019 dan 9 Maret 2020. Peneliti memilih media itu karena hanya BangkaPos yang mengangkat dan mengulas permasalahan tersebut secara mendalam. 
Data sekunder diperoleh melalui studi pustaka dengan mempelajari buku-buku, artikel, berbagai situs di internet yang relevan dengan penelitian ini, sedangkan model framing yang digunakan adalah Zhongdan Pan dan Gerald M. Kosicki.

Adapun unit analisis data pada penelitian ini disampaikan selengkapnya pada Tabel 2 sedangkan Tabel 1 merupakan penjelasan framing model Zhongdan Pan dan Gerald M. Kosicki.

Tabel 1. Perangkat Framing Zhongdan Pan dan Gerald M. Kosicki

\begin{tabular}{|c|c|c|}
\hline Struktur & Perangkat Framing & Unit yang Diamati \\
\hline $\begin{array}{l}\text { SINTAKSIS: } \\
\text { Cara wartawan menyusun fakta }\end{array}$ & Skema berita & $\begin{array}{l}\text { Headline, lead, latar informasi, kutipan } \\
\text { sumber, pernyataan, penutup }\end{array}$ \\
\hline $\begin{array}{l}\text { SKRIP: Cara } \\
\text { mengisahkan fakta }\end{array}$ & Kelengkapan berita & $5 \mathrm{~W}+1 \mathrm{H}$ \\
\hline $\begin{array}{l}\text { TEMATIK: Cara wartawan menulis } \\
\text { fakta }\end{array}$ & $\begin{array}{ll}\text { 1. } & \text { Detail } \\
\text { 2. } & \text { Koherensi } \\
\text { 3. } & \text { Bentuk kalimat } \\
\text { 4. } & \text { Kata ganti } \\
\end{array}$ & $\begin{array}{l}\text { Paragraph, proposisi, kalimat, hubungan } \\
\text { antar kalimat }\end{array}$ \\
\hline $\begin{array}{l}\text { RETORIS: Cara } \\
\text { menekankan fakta }\end{array}$ & $\begin{array}{l}\text { 1. Leksikon } \\
\text { 2. Grafis } \\
\text { 3. metafora }\end{array}$ & Kata, idiom, gambar/foto, grafik \\
\hline
\end{tabular}

Sumber: Eriyanto, 2002: 256 
Tabel 2. Unit Analisis Data

\begin{tabular}{|c|c|c|}
\hline Tgl Terbit & Jam Terbit & Judul Berita \\
\hline 2 Nov 2019 & 18:17 WIB & $\begin{array}{l}\text { Breaking News: Wagub Abdul Fatah Dikabarkan Dikepung Warga di Sijuk } \\
\text { Belitung, } 6 \text { Sapol PP Terluka }\end{array}$ \\
\hline 2 Nov 2019 & 18:30 WIB & $\begin{array}{l}\text { Breaking News: Mobil Wagub Abdul Fatah Rusak Akibat Kericuhan } \\
\text { Penertiban Tambang Sijuk Belitung }\end{array}$ \\
\hline 2 Nov 2019 & 18:36 WIB & $\begin{array}{l}\text { BREAKING NEWS - Wagub Bangka Belitung Abdul Fattah Dikabarkan } \\
\text { Terluka, Begini Informasi Terkini }\end{array}$ \\
\hline 2 Nov 2019 & 18:39 WIB & $\begin{array}{l}\text { Wagub Bangka Belitung Abdul Fatah Dikepung, Mobil Dirusak, } 6 \text { Satpol } \\
\text { PP Terluka di Sijuk }\end{array}$ \\
\hline 2 Nov 2019 & 19:05 WIB & $\begin{array}{l}\text { Kericuhan Penertiban Tambang di Belitung, Sopir Satpol PP Belitung } \\
\text { Timur Alami Patah Tangan }\end{array}$ \\
\hline 2 Nov 2019 & 19:16 WIB & $\begin{array}{l}\text { Kerusuhan di Sijuk Belitung, Wagub Babel Dikabarkan Terluka, } 6 \text { Satpol } \\
\text { PP Luka-luka, Mobdin Rusak }\end{array}$ \\
\hline 2 Nov 2019 & 20:05 WIB & $\begin{array}{l}\text { Ketua DPRD Minta Kapolda Usut Kasus Penambang Intimidasi dan Rusak } \\
\text { Mobil Wagub Bangka Belitung }\end{array}$ \\
\hline 2 Nov 2019 & $20: 32$ WIB & $\begin{array}{l}\text { Kondisi Terkini Wagub Bangka Belitung Setelah Mobilnya Dirusak Saat } \\
\text { Penertiban Tambang Ilegal }\end{array}$ \\
\hline 2 Nov 2019 & 21:16 WIB & $\begin{array}{l}\text { Gubernur Babel Erzaldi Rosman Sayangkan Massa Kepung Wagub dan } \\
\text { Rusak Mobil Dinas }\end{array}$ \\
\hline 2 Nov 2019 & 21:41 WIB & $\begin{array}{l}\text { Kronologi Aksi Anarkis Penambang Ilegal di Sijuk Wagub Diintimidasi } \\
\text { Mobil Dirusak Petugas Luka-luka }\end{array}$ \\
\hline 2 Nov 2019 & $21: 56$ WIB & $\begin{array}{l}\text { Gubernur Erzaldi Akan Bahas Penyerangan Satpol PP dan Wagub Fatah } \\
\text { di Belitung Bersama Forkominda }\end{array}$ \\
\hline 2 Nov 2019 & $22: 13$ WIB & $\begin{array}{l}20 \text { Orang Anggota Satpol PP Alami Luka-Luka, Motor Hingga HP Dibakar } \\
\text { Akibat Kericuhan di Belitung }\end{array}$ \\
\hline 2 Nov 2019 & 23:42 WIB & $\begin{array}{l}\text { Aksi Anarkis Penambang Ilegal di Desa Sijuk Berakhir Damai Ini } \\
\text { Kesepakatan Kedua Belah Pihak }\end{array}$ \\
\hline 3 Nov 2019 & 00:05 WIB & $\begin{array}{l}\text { Kapolres dan Dandim } 0414 \text { Belitung Kecewa Tak Ada Kordinasi } \\
\text { Penertiban Tambang }\end{array}$ \\
\hline 3 Nov 2019 & 13:08 WIB & $\begin{array}{l}\text { Kapolres Kecewa Penertiban TI di Desa Sijuk Tak Kordinasi, Jangan } \\
\text { Sampai Dianggap Tak Bertindak }\end{array}$ \\
\hline 3 Nov 2019 & 17:03 WIB & $\begin{array}{l}\text { Razia Berakhir Ricuh, Bupati Belitung Sebut Satpol PP Tak Ada } \\
\text { Koordinasi dan Langsung Bakar TI Rajuk }\end{array}$ \\
\hline 3 Nov 2019 & $20: 53$ WIB & $\begin{array}{l}\text { Kepala Satpol PP Bangka Belitung Yamowa Harefa Malam Ini Diambil } \\
\text { Keterangan di Polres Belitung }\end{array}$ \\
\hline 3 Nov 2019 & $21: 17$ WIB & $\begin{array}{l}\text { Razia TI Ricuh, Gubernur Bangka Belitung Tegaskan Lanjut Proses } \\
\text { Hukum Agar Tak Jadi Preseden Buruk }\end{array}$ \\
\hline 3 Nov 2019 & 21:37 WIB & $\begin{array}{l}10 \text { Orang Diperiksa Polres Belitung Terkait Ricuh Penertiban TI, Dari } \\
\text { Penambang Hingga Kasatpol PP }\end{array}$ \\
\hline 4 Nov 2019 & 19:08 WIB & $\begin{array}{l}\text { Keselamatan Wagub Terancam, Fraksi Gerindra Surati Gubernur Minta } \\
\text { Kasat Pol PP Diganti }\end{array}$ \\
\hline 5 Nov 2019 & 17:04 WIB & $\begin{array}{l}\text { Pasca Kericuhan Penertiban Tambang di Sijuk, Kasatpol PP Bangka } \\
\text { Belitung Benarkan Sudah Lapor Polisi }\end{array}$ \\
\hline 6 Nov 2019 & 15:56 WIB & $\begin{array}{l}\text { Besok DPRD Bangka Belitung Gelar Dengar Pendapat Soal Penertiban } \\
\text { Tambang }\end{array}$ \\
\hline 7 Nov 2019 & 16:00 WIB & $\begin{array}{l}\text { Wagub Bangka Belitung Abdul Fatah Beberkan Kronologis Kericuhan } \\
\text { Penertiban Tambang llegal di Sijuk }\end{array}$ \\
\hline 7 Nov 2019 & 17:41 WIB & $\begin{array}{l}\text { Wakil Gubernur Bangka Belitung Abdul Fattah Dipukul Berkali-kali, } \\
\text { Didorong Hingga Jatuh Terduduk }\end{array}$ \\
\hline 7 Nov 2019 & 18:02 WIB & $\begin{array}{l}\text { Anggota DPRD Bangka Belitung Pertanyakan Kinerja Polda Babel Lambat } \\
\text { Tangani Kasus Tambang Belitung }\end{array}$ \\
\hline 9 Maret 2020 & 11.24 WIB & $\begin{array}{l}\text { Anggotanya ditetapkan Tersangka Kasus Sijuk, Kasatpol PP: Satu Sakit, } \\
\text { Semua lkut Sakit }\end{array}$ \\
\hline
\end{tabular}




\section{HASIL PENELITIAN}

Berikut ini adalah pembahasan terkait struktur: Sintaksis (cara wartawan menyusun fakta); Skrip (cara wartawan mengisahkan fakta); Tematik (cara wartaan dalam menulis fakta), dan Retoris (cara dalam penekanan fakta), yakni (1) Headline (Breaking News Lead): Wakil Gubernur Abdul Fatah; (2) Latar Informasi: Dikabarkan dikepung Warga di Sijuk Belitung; (3) Kutipan Sumber: Direktur RSUD Marsidi Judono dr. Hendra; (4) Pernyataan: Saya baru dapat info dari Direktur RSUD bahwa di lokasi saat ini masih ada Wakil Gubernur yang mengalami cedera hidung dan sekarang masih di lokasi kejadian; (5) Penutup: 6 Satpol PP Terluka.

\begin{tabular}{|c|c|}
\hline Unit Sintaksis & Uraian / Analisa \\
\hline Headline & $\begin{array}{l}\text { Breaking News } \\
\text { Berita terbaru adalah suatu berita yang baru dan saat ini sedang terjadi. }\end{array}$ \\
\hline Lead & $\begin{array}{l}\text { Wakil Gubernur Abdul Fatah } \\
\text { Dari kalimat tersebut lebih menekankan/menonjolkan menempatkan posisi jabatan } \\
\text { seseorang di awal kalimat berita sebagai penarik antusias pembaca dikarenakan } \\
\text { Abdul Fatah adalah wakil gubernur yang berpasangan dengan gubernur Erzaldi } \\
\text { Rosman. }\end{array}$ \\
\hline Latar Informasi & $\begin{array}{l}\text { Dikabarkan dikepung Warga di Sijuk Belitung } \\
\text { Penulisan kalimat tersebut menginformasikan bahwa telah terjadi sesuatu terhadap } \\
\text { Wagub Babel, telah terjadi sesuatu kepada orang nomor } 2 \text { di Bangka Belitung. }\end{array}$ \\
\hline Kutipan Sumber & $\begin{array}{l}\text { Direktur RSUD Marsidi Judono dr. Hendra keenam korban mengalami luka memar } \\
\text { hingga luka bagian kepala. Keenam korban juaga merupakan petugas Satpol PP } \\
\text { Provinsi Bangka Belitung. } \\
\text { 1. Nurul Ihsan (40) dari Pangkalpinang Mengalami luka di bagian kepala. Dari } \\
\text { pengakuan, ia dipukul menggunakan kayu. Saat ini sudah ditangani, ada enam } \\
\text { jahitan di kepala. Saat ini pasien sedang istirahat di UGD } \\
\text { 2. Handi Pamungkas (35) dari Jakarta. Mengalami luka memar di lengan kanan. } \\
\text { Tidak ada luka serius. } \\
\text { 3. Mustarifah (21) Bangka Tengah. Mengalami luka di jari tengah dan telunjuk dan } \\
\text { tulangnya keluar. Tapi pihak RSMJ belum memastikan lebih lanjut karena } \\
\text { sekarang pasien sedang dibawa ke ruang radiologi. } \\
\text { 4. Permana Yusuf (39) dari Sungailiat. Mengalami cedera kepala belakang. Pasien } \\
\text { mengatakan agak pusing dan muntah. Saat ini sedang di rontgen. } \\
\text { 5. Pak lim (33) dari Pangkalpinang. Mengalami luka robek di kepala sudah dievakuasi } \\
\text { dan dijahit. Juga mengalami bengkak lengan kiri tapi belum dipastikan apakah } \\
\text { mengalami patah tulang. Sat ini sedang di ruang UGD menunggu hasil rontgen. } \\
\text { 6. Darmawi (40) Pangkalpinang Mengalam luka di perut kiri dan bengkak tangan kiri. }\end{array}$ \\
\hline Pernyataan & $\begin{array}{l}\text { Direktur RSUD Marsidi Judono dr. Hendra. "Saya baru dapat info dari Direktur RSUD } \\
\text { bahwa di lokasi saat ini masih ada Wakil Gubernur yang mengalami cedera hidung } \\
\text { dan sekarang masih di lokasi kejadian }\end{array}$ \\
\hline Penutup & $\begin{array}{l}6 \text { Satpol PP Terluka. Berdasarkan pantauan Posbelitung.co, saat ini anggota Satpol PP } \\
\text { Provinsi Bangka Belitung sedang berada di depan ruang UGD. }\end{array}$ \\
\hline
\end{tabular}

Skrip (Cara Wartawan Mengisahkan Fakta) menampilkan: Why: Wagub Babel dikepung warga; Who: Abdul Fatah; What: Breaking News; Where: Sijuk Belitung; When: Sabtu, 2 November 2019, dan How: Faktor penyebab: akibat penertiban tambang timah illegal

\section{Sistem Tematik (Cara Wartawan Menulis Fakta).}

Penyusunan paragraph bersifat parsial. Paragraph pertama: Wakil Gubernur (Wagub) Kepulauan Babel Abdul Fatah dikabarkan dikepung warga sekitaran Kecamatan Sijuk, Kabupaten Belitung, akibat penertiban tambang timah ilegal. 
Paragraph Kedua: mengisahkan dari pengepungan tersebut. Wakil Gubernur (Wagub) Kepulauan Babel Abdul Fatah dikabarkan selamat. Pasca kejadian sempat singgah di Mapolsek Sijuk mengenakan kaos putih lengan panjang celana kain abu-abu dikawal anggota Polres Belitung. Belum sempat duduk, Abdul Fattah kembali keluar Mapolsek dan berbincang dengan Kabag Ops Polres Belitung Kompol Erlicshon beserta jajarannya. "Tadi saya janji di kantor desa jadi kita ke sana saja". Terjadi perubahan tempat kemudian, seluruh rombongan berbegas menuju Kantor Camat Sijuk untuk bertemu warga setempat

Paragraph Ketiga, pembahasan pertemuan Wakil Gubernur Kepulauan Babel Abdul Fattah didampingi Kapolres Belitung AKBP Yudhis Wibisana, Dandim 0414 Belitung Letkol Inf. Indra Padang dan Kapolsek Sijuk Iptu Abdul Haris, melakukan pembicaraan dengan perwakilan warga di Kantor Camat Sijuk, Kabupaten Belitung

Paragraph Keempat, tentang korban bentrok fisik pengepungan warga yang menciderai anggota Satpol PP Provinsi enam orang dengan mengindentifikasi luka-luka yang dialami pasca kejadian. Penyebabnya kena pukul kayu atau senjata tajam parang. Semuanya sudah ditangani. Info Direktur RSUD Marsidi Judono dr. Hendra

Paragraph Kelima, disampaikan kondisi wagub, dari Direktur RSUD. Dia menyampaikan di lokasi masih ada Wakil Gubernur yang mengalami cedera hidung dan sekarang masih di lokasi kejadian.

Wartawan menulis berita lebih condong mengangkat nama Abdul Fatah berulang kali, dari awal paragraph sampai paragraph terakhir, dan memposisikan kondisi wagub tidak aman, padahal di awal paragraph dituliskan kondisi wagub dalam keadaan selamat.

Di sisi lain, wartawan menekankan kondisi yang dialami oleh Satpol PP, mengalami luka-luka terkena benda tajam parang akibat bentrok fisik dengan para penambang atau warga saat dilakukan penertiban tambang timah illegal.

Dari kelima paragraph tersebut, tampak lebih banyak membahas kondisi Wagub Abdul Fatah dan menjadi sorotan pemberitaan wartawan.

\section{Proporsi}

Kalimat yang banyak digunakan dalam pemberitaan adalah kalimat aktif dengan menempatkan objek-objek dari subjek Abdul Fatah yakni:

(1) Wagub Abdul Fatah dikabarkan dikepung warga di Sijuk Belitung. Dalam kamus Bahasa Indonesia (KBBI) dikepung bermakna dikelilingi oleh sesuatu (warga) sementara kalimat (frasa) dikabarkan dapat diartikan sebagai suatu kejadian yang baru saja terjadi, belum tentu kabar tersebut sesuai fakta benar adanya. Kalimat tersebut lebih menekankan Abdul Fatah sebagai objek yang tidak berdaya;

(2) Dari pengepungan tersebut Wagub Abdul Fatah dikabarkan selamat. Penempatan kata selamat adalah wujud dari suatu kondisi di mana dalam kejadian pengepungan tersebut yaitu kejadian yang baru saja terjadi, Abdul Fatah dalam keadaan baik. Penekanan kata selamat ini tidak berbanding lurus dengan objek lain berita yang ditulis wartawan, anggota satpol PP dikabarkan mengalami luka. Hal ini menunjukkan penekanan aspek informasi ke publik bahwa yang menjadi korban dari pengepungan tersebut adalah anggota Satpol PP;

(3) daftar Anggota Satpol PP yang menjalani perawatan akibat pengepungan wagub di Sijuk. Dalam kalimat tersebut objek yang menjadi korban adalah Satpol PP dari subjek Abdul Fatah. Pernyataan ini menekankan kondisi yang sebenarnya terjadi dan yang diuntungkan adalah popularitas wagub walaupun target pengepungan sebenarnya bukan wagub. 
Dalam hal ini wartawan memberikan fakta bahwa penertiban tambang timah illegal yang dilakukan oleh Satpol PP bersama wagub merupakan kewenangan pemerintah provinsi sehingga tidak ada koordinasi dengan Pemerintah Kabupaten Belitung.

\section{Hubungan Antarkalimat}

Wartawan dalam penyajian berita yang berkaitan dengan hubungan antarkalimat lebih banyak menggunakan perbandingan, kata sambung "dan", untuk membandingkan sosok Abdul Fatah dengan Satpol PP.

Kata keterangan "berdasarkan", "dikabarkan" sebagai penghubung kalimat sering digunakan wartawan dalam penyajian berita untuk menjelaskan kejadian tersebut. Selain itu ada kata "dari", "kemudian", "sementara" digunakan sebagai penghubung kalimat.

\section{Sistem Retoris (Cara Wartawan Menekankan Fakta)}

Kata-kata yang digunakan: (1) Wagub; (2) Abdul Fatah; (3) Dikepung, dan (4) Tambang Timah. Hubungan kata secara retoris ialah bagaimana wartawan menekankan fakta yang disampaikan, menempatkan Abdul Fatah sebagai seseorang yang penting untuk ditonjolkan.

Fakta-fakta yang dihadirkan dalam proses pemberitaan ini dari narasumber menunjukkan tidak ada keberpihakan media terhadap pemerintah. Dengan demikian kontruksi fakta dengan menggunakan kata bersifat netral dari media BangkaPos.com.

Idiom yang digunakan dalam pemberitaan tersebut adalah sebagai berikut; (1) Dikeroyok. Dalam kamus Bahasa Indonesia (KBBI) dikeroyok bermakna serangan beramairamai (orang banyak) atau perkelahian beramai-ramai; (2) Anarkis. Dalam kamus KBBI berarti hal tidak adanya pemerintahan, undang-undang, peraturan, atau ketertiban. Umumnya, kata-kata tersebut digunakan untuk mengartikan "chaos", atau "tanpa tatanan,". Akibatnya, kaum anarkis dianggap menginginkan kekacauan sosial serta kembali ke "hukum rimba"; (3) Intimidasi. Dapat diartikan sebagai tindakan menakut-nakuti (terutama untuk memaksa orang atau pihak lain berbuat sesuatu); gertakan; ancaman; (4) Terancam. Dapat diartikan sebagai kondisi dimana posisi dalam bahaya atau dibawah ancaman; (5) Tidak Koordinasi. Perihal mengatur suatu organisasi atau kegiatan sehingga peraturan dan tindakan yang akan dilaksanakan tidak saling bertentangan atau simpang siur; (6) Preseden. Sebagai sesuatu hal yang telah terjadi lebih dahulu dan dapat dipakai sebagai contoh.
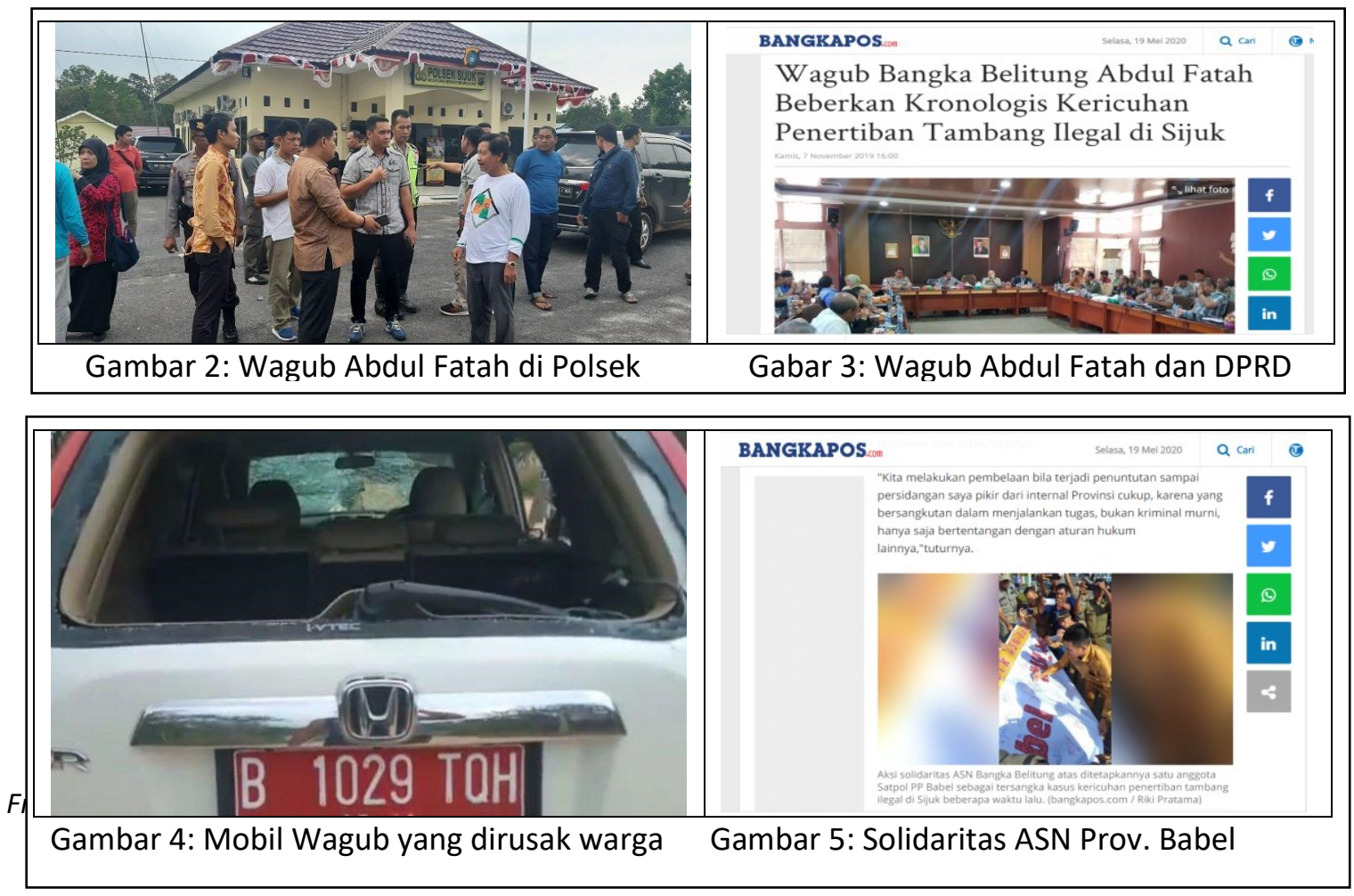
Hubungan aktifitas Wagub Abdul Fatah di Polsek, dan rapat dengar pendapat dengan DPRD Provinsi Bangka Belitung, pengrusakan mobil dinas Wagub Abdul Fatah dan penggalangan tanda tangan sebagai bentuk solidaritas ASN kepada Satpol PP yang dijadikan tersangka dalam kasus Sijuk Belitung adalah hubungan yang parsial. Hubungan konstruksi tersebut dengan segmen yang sedang dibahas oleh narasumber berkaitan dengan kasus penertiban tambang timah illegal di Sijuk Belitung.

BangkaPos.com berusaha menampilkan porsi yang sesuai dengan pemberitaan kepada publik sebagai bentuk independensinya sebagai media lokal pertama di Bangka Belitung dengan menunjukkan netralitas sesuai fakta yang ada.

Di samping itu, hubungan kontruksi sosial yang dibangun media BangkaPos.com memperlihatkan politisasi kekuasaan dan dilematisasi di mana posisi Satpol PP sebagai abdi negara yang menegakkan Peraturan Daerah dianggap bersalah lantaran membakar alat-alat tambang ilegal.

BangkaPos.com menayangkan berita terkait peristiwa tersebut adalah sebagai berikut: (1) pada 2/11/2019 sebanyak 13 terbitan; (2) terbitan 3/11/2019 sebanyak 6 kali; kemudian (3) pada 4, 5, dan 6 November 2019 sebanyak satu kali; (4) pada 7/ November 2019 tiga kali; dan(5) pada 9 November satu pemberitaan. Khusus pada kejadian, 2 November 2019, ada 13 kali pemberitaan.

\section{KESIMPULAN}

BangkaPos.com memberitakan Wakil Gubernur Bangka Belitung dikepung saat melakukan razia tambang illegal, sehingga publik mengetahui peristiwa ricuh yang terjadi dan menyebabkan Satpol PP terluka sedangkan wakil gubernur dalam kondisi aman.

Kontruksi atas peristiwa tersebut adalah kontruksi isi media yang dilakukan oleh media sebagai tipe hubungan antara pemerintah Provinsi Bangka Belitung dengan BangkaPos.com sebagai type Low-power source, high-power media: kekuatan media lebih besar, sehingga bebas untuk menentukan agendanya sendiri, serta dapat pula memberitakan, menambah ataupun mengurangi intensitas pemberitaan tertentu.

BangkaPos.com merupakan agen konstruksi realitas (menganut paham konstruksionis) dan berada di dimensi sosiologis, karena sebagai organisasi kompleks yang memiliki kebijkan tersendiri.

\section{REFERENSI}

Berger, P.L \& Luckmann, T. (1990). Tafsir Sosial Atas Kenyataan. Risalah tentang Sosiologi Pengetahuan. LP3ES: Jakarta.

Baran, S.J \& Dennis K.D. (2009). Teori Komunikasi Massa, Dasar, Pergolakan dan Masa Depan. Jakarta: Salemba Humanika.

Eriyanto. (2002). Analisis Framing Konstruksi, Ideologi dan Politik Media. Yogyakarta: LkiS. Eriyanto. (2005). Analisis Wacana, Suatu Pengantar. Yogyakarta: LKiS.

Hamad, I. (2004). Komunikasi Sebagai Wacana. Jakarta: La Tofi Enterprise.

Iriantara, Y. (2008). Media Relation Konsep, Pendekatan dan Praktik. Bandung: Simbiosa Rekatama Media.

Maryani, E. (2018). Developing Social Solidarity through Digital Media, Jurnal Komunikasi Ikatan Sarjana Komunikasi Indonesia, 3(1), 12-17.

McQuail, D. (2011). Teori Komunikasi Massa McQuail. Jakarta: Salemba Humanika.

Morissan. (2010). Teori Komunikasi Massa. Bogor: Ghalia Indonesia.

Pawito. (2007). Penelitian Komunikasi Kualitatif. Yogyakarta: PT. LKiS Pelangi Aksara. 
Ritonga, R., Nugroho, E., Handoko, D. (2019). Struggle of Meaning and the Jokowi Myth in the 2018 Asian Games Opening Video. Jurnal Komunikasi: Malaysian Journal of Communication, 35(1), 137-155.

Ritonga, R \& Syahputra, I. (2019). Citizen Journalism and Public Participation in the Era of NewMedia in Indonesia: From Street to Tweet, Media and Communication, 7(3), 7990.

Ritonga, R., Murwani, E. \& Ritonga, S. (2017). Gender Awareness of Maria Hartiningsih as Daily Kompas Reporter, Jurnal Komunikasi Ikatan Sarjana Komunikasi Indonesia, 2(2), 82-91

Suraya, S. (2019). Journalist Credibility Based on Digital Media Used, Jurnal Komunikasi Ikatan Sarjana Komunikasi Indonesia, 4(1), 26-34.

Suryawati, I. (2011). Jurnalistik Suatu Pengantar Teori \& Praktik. Bogor: Ghalia Indonesia.

Sudibyo, A. (2001). Politik Media dan Pertarungan Wacana. Yogyakarta: LKiS.

Sobur, A. (2012). Analisis Teks Media: Suatu pengantar untuk Analisis Wacana, Analisis Semiotik dan Analisis Framing. Bandung: PT Remaja Rosdakarya.

Tamburaka, A. (2012). Agenda seting Media Massa. Jakarta: Rajawali Pers. 